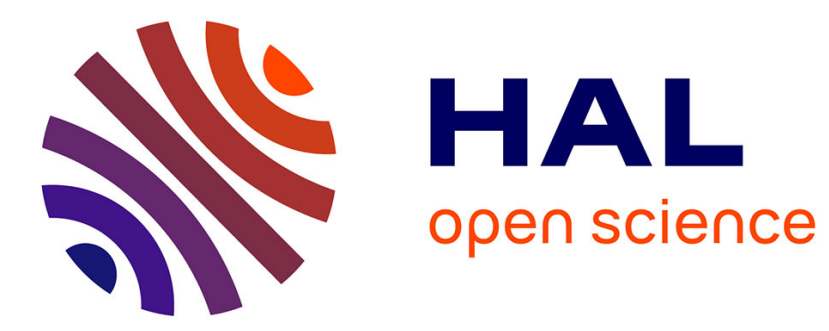

\title{
Applications of single-beam photothermal analysis
}

\author{
R. Schork, S. Krügel, C. Schneider, L. Pfitzner, H. Ryssel
}

\section{To cite this version:}

R. Schork, S. Krügel, C. Schneider, L. Pfitzner, H. Ryssel. Applications of single-beam photothermal analysis. Journal de Physique IV Proceedings, 1994, 04 (C7), pp.C7-27-C7-30. 10.1051/jp4:1994707 . jpa-00253148

\section{HAL Id: jpa-00253148 https://hal.science/jpa-00253148}

Submitted on 1 Jan 1994

HAL is a multi-disciplinary open access archive for the deposit and dissemination of scientific research documents, whether they are published or not. The documents may come from teaching and research institutions in France or abroad, or from public or private research centers.
L'archive ouverte pluridisciplinaire HAL, est destinée au dépôt et à la diffusion de documents scientifiques de niveau recherche, publiés ou non, émanant des établissements d'enseignement et de recherche français ou étrangers, des laboratoires publics ou privés. 


\title{
Applications of single-beam photothermal analysis
}

\author{
R. Schork, S. Krügel*, C. Schneider, L. Pfitzner and H. Ryssel \\ Fraunhofer-Institut für Integrierte Schaltungen, Artilleriestrasse 12, 91052 Erlangen, Germany \\ * Friedrich-Schiller-Universität Jena, Institut für Festkörperphysik, Helmholtzweg 3, 07743 Jena, \\ Germany
}

\begin{abstract}
Thermal wave techniques have gained increasing attention in semiconductor process control because they are nondestructive and noncontacting. Recently, in-line and in situ implementations have been investigated. This paper will demonstrate that thermal wave analysis is capable of measuring two major parameters, metal layer thickness and temperature.
\end{abstract}

\section{INTRODUCTION}

Noncontacting measurement techniques are of growing interest especially in semiconductor manufacturing where the avoidance of contamination is of essential importance. Clean and nondestructive methods are required for in-line and in situ process control.

There are only a few methods for thickness measurements of opaque films and temperature measurements which are noncontacting. Eddy current sensors for thickness measurements or optical pyrometry for temperature measurements are possible methods. But because of the disadvantages of these techniques they have only a limited application field. The eddy current technique has poor spatial resolution and accuracy for very thin metal layers. The problems of pyrometry are unknown emissivity and radiation from the environment reflected by the sample. In chapter 2 and 3 it will be demoustrated that thermal wave analysis is capable of measuring thin metal layer thicknesses with a high spatial resolution down to $4 \mu \mathrm{m}$ and temperature with high accuracy.

The thermal wave (TW) system used in this study is described in more detail elsewhere [1]. It uses two semiconductor lasers emitting at $785 \mathrm{~nm}$ and modulated with frequencies between $100 \mathrm{kHz}$ and $1.2 \mathrm{MHz}$ with a $10 \mathrm{kHz}$ difference. Because of this difference, a frequency conversion takes place in the sample, such that a $10 \mathrm{kHz}$ reflection signal is detected from which the TW signal K (conversion coefficient [1]) can be calculated. Since semiconductor lasers are used, this TW system is very small and compact, and thus suitable for in-line and in situ applications.

\section{METAL LAYER THICKNESS MEASUREMENT}

Nondestructive and noncontacting thickness measurements of opaque films are of growing interest especially in metallization processes in semiconductor manufacturing. For transparent thin films, optical methods like ellipsometry and reflection spectrophotometry are used. For opaque films, however, a different kind of wave energy must be used [2]. Thermal waves have properties similar to optical waves. 
Reflectance at the interface between two layers with different thermodynamic parameters can be treated like optical reflectance and interference. This means that the response function depends on the film thickness. Thernal wave analysis is capable of measuring thin metal layer very accurately if the following conditions are fulfilled: 1 . The thermal modulation factor $\mathrm{dR} / \mathrm{dT}$ should be greater than $10^{-6} \mathrm{~K}^{-1} . \mathrm{dR} / \mathrm{dT}$ depends on the wavelength of the laser. The system used in this study with a semiconductor laser emitting at $785 \mathrm{~nm}$ has a maximum TW signal for Al layers. 2. Smooth surface. 3. The thermal conductivity of the sublayer should be low relatively to the top layer.

A material of interest in semiconductor technology is $\mathrm{Al}$ on $\mathrm{SiO}_{2}$. Results for this structure are shown in the following figures. Fig. 1 shows the dependence of the absolute value of $K$ versus the thickness of an aluminum layer on $1 \mu \mathrm{m}$ thermally oxidized silicon wafers. The highest value and a high thickness sensitivity are achieved for thin aluminum layers. Repeatability is better than $1 \%$ between $50 \mathrm{~nm}$ and $1000 \mathrm{~nm}$ corresponding to typical layer thicknesses in semiconductor processes. Above $1 \mu \mathrm{m}$ the sensitivity decreases. The absolute accuracy of TW thickness measurement depends mainly on the accuracy of the calibration samples. Using the curve in Fig. 1 as a calibration curve, a thickness mapping has been performed (Fig. 2). Since the measurement spot is about $4 \mu \mathrm{m}$, a high resolution mapping or measurements of structured wafers are possible. One point takes only a few milliseconds of measurement time, therefore, this method is suitable for real-time process control.
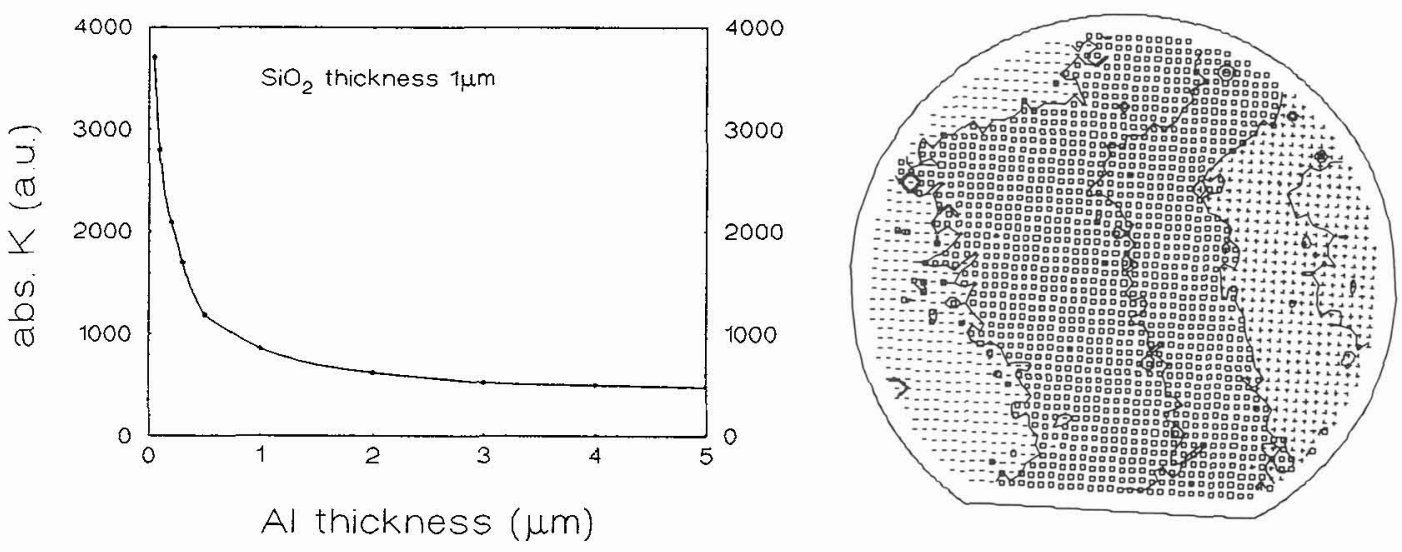

Fig. 1 Dependence of the thermal wave signal on the thickness of $\mathrm{Al}$ on $\mathrm{SiO}_{2}$

Fig. 2 Thickness mapping for evaporated Al, mean value; $97.6 \mathrm{~nm}$, standard deviation; $5.80 \%$

Fig. 3 and 4 show the effect of a $\mathrm{SiO}_{2}$ sublayer between the $\mathrm{Al}$ layer and the $\mathrm{Si}$ substrate. The TW signal increases with the thickness of the $\mathrm{SiO}_{2}$ sublayer. $\mathrm{SiO}_{2}$ has a very low thermal conductivity $(\mathrm{k}=1.4 \mathrm{~W} / \mathrm{mK})$ compared to $\mathrm{Al}(\mathrm{k}=238 \mathrm{~W} / \mathrm{mK})$ and $\mathrm{Si}(\mathrm{k}=140 \mathrm{~W} / \mathrm{mK})$ and is, therefore, acting as a temperature barrier. By decreasing the thickness of the temperature barrier, the thermal wave penetrates deeper into the silicon substrate which causes a reduction of the TW amplitude. The TW signal from the $\mathrm{SiO}_{2}$ sublayer saturates for a thick $\mathrm{SiO}_{2}$ sublayer. This saturation depends on the thickness of the Al layer and on the modulation frequency, as shown in Fig. 3 and 4. The modulation frequency in Fig. 3 was $100 \mathrm{kHz}$ and $1.2 \mathrm{MHz}$ in Fig. 4. Higher modulation frequencies and thicker Al layers cause the same effect, a reduction of the penetration depth of the thermal wave in the sublayer and, therefore, a shift of the saturation to thinner $\mathrm{SiO}_{2}$ sublayer, shown in Fig.4. 


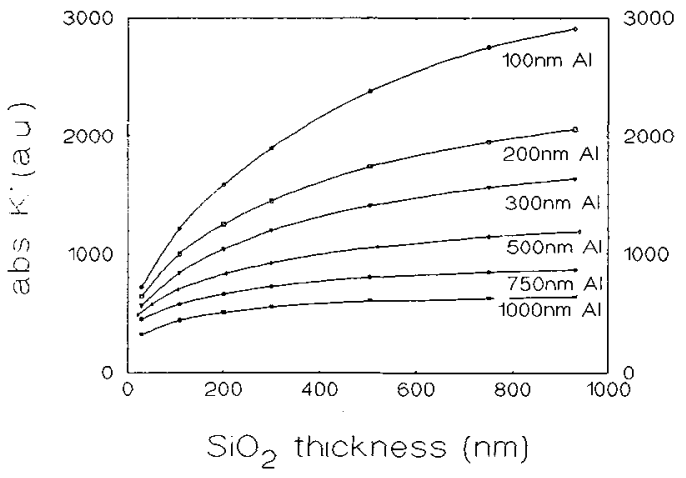

Fig. 3 Dependence of the TW signal on the thickness of the $\mathrm{SiO}_{2}$ sublayer, $\mathrm{f}=100 \mathrm{kHz}$.

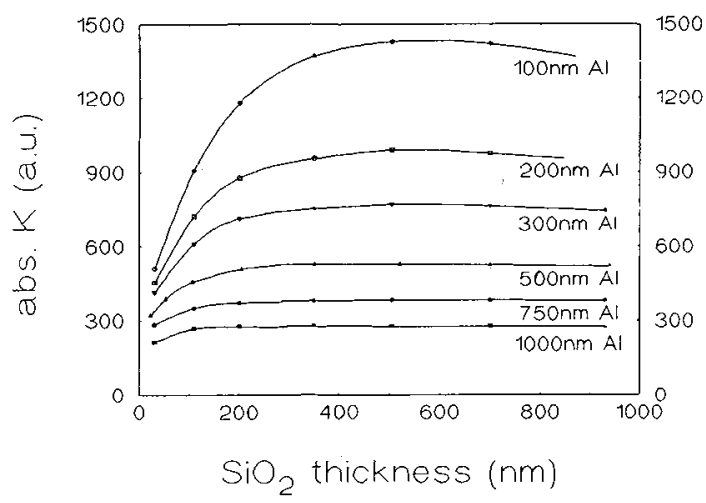

Fig. 4 Dependence of the TW signal on the thickness of the $\mathrm{SiO}_{2}$ sublayer, $\mathrm{f}=1.2 \mathrm{MHz}$.

Because of the dependence of the TW signal on the thickness of the Al layer and the sublayer, usually one parameter should be known for the determination of the other. But there are two possibilities to overcome this problem. The first can be seen in Fig. 4. The curves for Al layers thicker than $300 \mathrm{~nm}$ and $\mathrm{SiO}_{2}$ sublayers greater than $200 \mathrm{~nm}$ are flat. This means that by increasing the modulation frequency to $1.2 \mathrm{MHz}$ or above, there exists a wide $\mathrm{Al}$ range where the thickness of the $\mathrm{SiO}_{2}$ sublayer has almost no effect on the TW signal. The second possibility is to analyze the dependence of the TW signal on the modulation frequency. The frequency sweep form function (TW signal versus $1 / \sqrt{\mathrm{f}}$ ) provides information on the $\mathrm{Al}$ surface layer and the $\mathrm{SiO}_{2}$ sublayer. Therefore, the sweep form function can be used together with a multilayer model for determination of both, thicknesses of the $\mathrm{Al}$ layer and the $\mathrm{SiO}_{2}$ sublayer.

\section{NONCONTACTING TEMPERATURE MEASUREMENT}

Possible temperature measurement methods are thermocouple measurement, pyrometry, interferometry, and dilatometry. But only pyrometry and interferometry are noncontacting. The main problems when measuring surface temperature using optical pyrometry are the unknown emissivity and radiation reflected by the sample [3]. Especially at low temperatures or when the sample is placed in a hot environment, the reflected flux may become larger than the emitted flux. Pyrometry is a fast and noncontacting method, but it is too inaccurate below $600^{\circ} \mathrm{C}$ for many applications [4]. Interferometry is accurate even at very low temperatures. However, this method is very slow and needs a glass substrate for measurement [5].

A fast and noncontacting method, especially in the low temperature range, is TW analysis. For temperature measurement, a sample with a high and temperature depending TW signal is necessary. For the measuring instrument described above, a sample with an Al layer on glass or an Al layer on oxidized silicon wafer shows a strong dependence of the TW signal on the temperature. Fig. 5 (Al layer on oxidized silicon) shows a nearly linear dependence of the TW signal on the temperature. Accuracy of the temperature measurement and repeatability was better than $1 \%$ in this case. A temperature mapping $\left(3 \times 3 \mathrm{~cm}^{2}\right)$ at the edge of a wafer lying on a hot plate is shown in Fig. 8. High sensitivity and repeatability allow a precise temperature detection and spatial resolution. 
Using semiconductor lasers emitting at $785 \mathrm{~nm}$ (photon energy $1.58 \mathrm{eV}$ ), Al has a maximum in the thermal modulation spectrum. Therefore, a temperature shift of the thermal modulation spectrum is supposed to be the reason for the strong temperature dependence of the TW signal. The promising results with the TW analysis may lead to a new temperature measurement technique. However, further investigations and the optimization of the TW system for temperature measurement will be necessary.

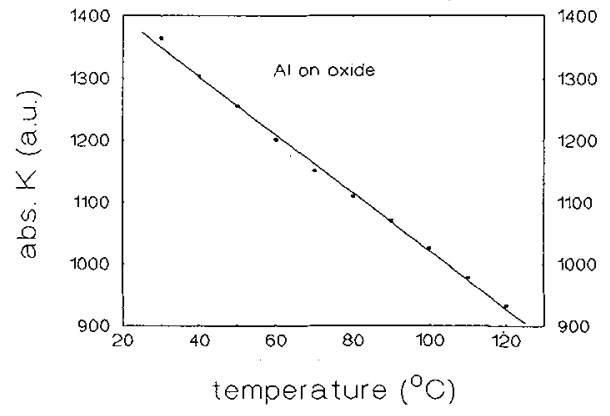

Fig. 5 Temperature dependence of the TW signal from an oxidized silicon wafer with a $100 \mathrm{~nm}$ evaporated Al layer

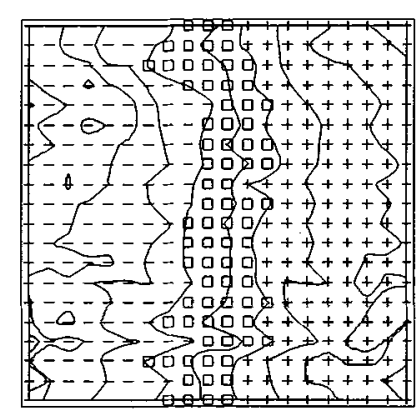

Fig. 6 Temperature mapping at the edge of a wafer lying on a hot plate, mean value; $67.07^{\circ} \mathrm{C}$, standard deviation; $7.35 \%$

\section{CONCLUSION}

It was demonstrated in this paper that thermal wave analysis is capable of measuring two major parameters in the metallization processes of semiconductor manufacturing, metal layer thickness and temperature. A material of interest for which this method is well suited is $\mathrm{Al}$ on $\mathrm{SiO}_{2}$. The TW signal is high for thin aluminum layers and very sensitive to thickness variation. The thickness range which is of interest in semiconductor processing, can be measured with a repeatability of better than $1 \%$ and absolute accuracy of a few nanometers depending on the calibration samples. The experimental results demonstrate that the TW system described above can also be used for accurate, fast and noncontacting temperature measurement, especially in the low temperature range with a high local resolution.

\section{References}

1. M. Wagner, and H. D. Geiler, Meas. Sci. Technol. 2 (1991) 1088.

2. M. B. Suddendorf, M. Liu, and M. G. Somekh Appl. Phys. Lett. 62 (25), (1993) 3256.

3. T. Loarer, J. J. Greffet, and M. Huetz-Aubert, Applied Optics, 29 (7) (1990) 979.

4. R. E. Sheets, Temperature Measurement and Control in a Rapid Thermal Processor, Mat. Tes. Soc. Symp., 52 (1) (1986).

5. R. A. Bond, S. Dzioba, H. M. Naguib, Temperature Measurement of Glass Substrates During Plasma Etching, J. off Vac. Soc. Techn., American Vacuum Society (1981). 